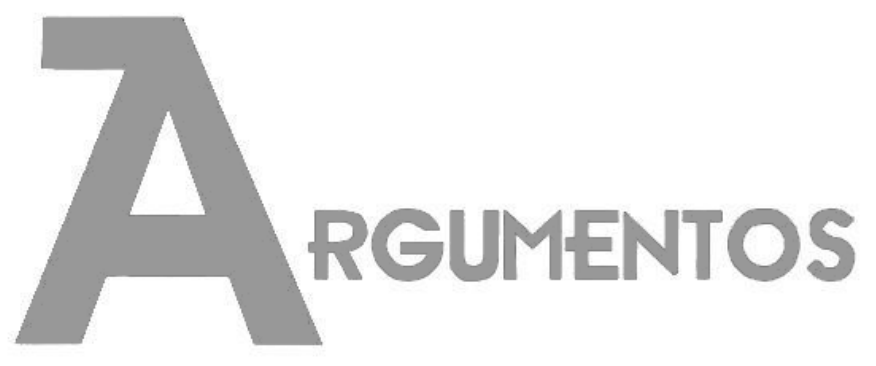

Vol. 18, n. 2, jul./dez. 2021 ISSN: 2527-2551 (online)

https://www.periodicos.unimontes.br/index.php/argumentos

\title{
Revisitando Canais e Lagoas, de Octavio Brandão
}

\author{
Filipe Pinheiro ${ }^{1}$
}

Recebido em: 14/01/2021

Aprovado em: 17/05/2021

Resumo: Passados quarenta anos da morte de Octavio Brandão e cem anos da publicação de Canais e Lagoas, sua primeira obra, e o livro ainda é pouco comentado pelos estudiosos do pensamento social brasileiro. Neste artigo pretendo me somar ao recente esforço de reapreciação da obra de Brandão, através de um resgate crítico de Canais e Lagoas. Trato das condições que levaram à produção da obra, como as três palestras proferidas em Maceió enquanto o autor escrevia Canais e Lagoas, e também mapeio ecos do texto em sua interpretação marxista do Brasil. A partir desta análise, destaco o papel de Canais e Lagoas para a formação da visão de mundo de Octavio Brandão, e seu papel pioneiro para o posicionamento nacionalista e anti-imperialista do autor.

Palavras-chave: Octavio Brandão; Canais e Lagoas; Pensamento Social Brasileiro; História do Pensamento Econômico; História do Marxismo no Brasil.

\section{Revisitando Canais e Lagoas, por Octavio Brandão}

Resumen: Cuarenta años después de la muerte de Octavio Brandão y cien años después de la publicación de Canais e Lagoas (Canales y Lagunas), su primera obra, el libro es todavía poco comentado por los estudiosos del pensamiento social brasileño. En este artículo pretendo sumarme al reciente esfuerzo de revisión del trabajo de Brandão, a través de un rescate crítico de Canais e Lagoas. Me ocupo de las condiciones que llevaron a la producción de la obra, como las tres conferencias impartidas en Maceió mientras el autor escribía Canais e Lagoas, y también mapeo ecos del texto en su interpretación marxista de Brasil. De este análisis destaco el papel de Canais e Lagoas para la formación de la cosmovisión de Octavio Brandão y su papel pionero en la posición nacionalista y antiimperialista del autor.

Palabras clave: Octavio Brandão; Canais e Lagoas; Pensamiento Social Brasileño; Historia del Pensamiento Económico; Historia del Marxismo en Brasil.

\footnotetext{
${ }^{1}$ Graduado em Ciências Econômicas pela Universidade Federal do Rio de Janeiro (2013), mestre em economia pela Universidade Federal Fluminense (2016) e doutor em economia pela Universidade Federal Fluminense (2020). Atualmente é professor substituto do Departamento de Ciências Econômicas (DeCE) da Universidade Federal Rural do Rio de Janeiro (UFRRJ), Brasil. É pesquisador do Núcleo Interdisciplinar de Estudos e Pesquisas Sobre Marx e o Marxismo - NIEP-Marx/UFF e do Coletivo Marxistas da Rural (MAR). E-mail: leitepn@gmail.com. ORCID: http://orcid.org/0000-0002-1861-9827.
} 


\section{Revisiting Canais e Lagoas, by Octavio Brandão}

Abstract: Forty years after the death of Octavio Brandão and one hundred years after the publication of Canais e Lagoas (Channels and Lagoons), his first work, the book is still little commented by scholars of Brazilian social thought. In this article I intend to add myself to the recent effort to review Brandão's work, through a critical rescue of Canais and Lagoas. I deal with the conditions that led to the production of the work, such as the three lectures given in Maceió while the author wrote Canais e Lagoas, and I also map echoes of the text in his Marxist interpretation of Brazil. From this analysis, I highlight the role of Canais and Lagoas for the formation of Octavio Brandão worldview, and his pioneering role for the author's nationalist and anti-imperialist position.

Keywords: Octavio Brandão; Canais e Lagoas; Brazilian Social Thought; History of Economic Thought; History of Marxism in Brazil.

\section{Introdução}

Publicado com recursos próprios do autor, após sua chegada a cidade do Rio de Janeiro, em 1919, Canais e Lagoas (2001) resultou de uma série de incursões de Octavio Brandão pelo estado de Alagoas (AL), entre 1916 e 1917. Nos anos seguintes a estas incursões, Brandão realizou três conferências em Maceió, nas quais tratava dos aspectos geológicos, mineralógicos e sociais das terras, da gente e da história dos canais e das Lagoas Manguaba e Mundaú. Contudo, passados mais de quarenta anos após a morte de Brandão e cem anos desta publicação, realizada com esforço hercúleo, e ainda pouco se fala em Canais e Lagoas, do mesmo modo que pouco se fala também na contribuição de Octavio Brandão. Na introdução de Combates e Batalhas (1978), seu relato autobiográfico, Brandão se queixa por diversas vezes, não sem razão, dos ataques à sua memória e da falta de reconhecimento de seu trabalho, militância e reflexão pioneiros, atirados às águas do esquecimento.

Entretanto, o pouco reconhecimento parece em alguma medida combinar com o pioneirismo de Brandão em diversos aspectos. Em primeiro lugar, está entre os precursores do ensaio de interpretação histórica e geográfica socialmente engajado, inspirando-se sobretudo em Os Sertões, de Euclides da Cunha. Também é pioneiro da luta por um projeto de desenvolvimento nacional, através do apoio a luta pela estatização do petróleo, sem com isso perder de vista as questões ambientais - isso em tempos em que estas preocupações não eram tão amplamente arraigadas no senso comum como nos dias de hoje. Primeiro tradutor integral de O Manifesto Comunista e 
primeiro intérprete marxista da realidade brasileira que se tem notícia, com Agrarismo e Industrialismo: ensaio marxista-leninista sobre a revolta de São Paulo e a guerra de classes no Brasil - 1924 ([1926] 2006), Brandão também foi um dos primeiros intendentes ${ }^{2}$ comunistas eleitos no Brasil, em 1929, pelo Bloco Operário e Camponês (BOC) do Partido Comunista Brasileiro (PCB) - juntamente com o operário negro Minervino de Oliveira ${ }^{3}$. As áridas condições enfrentadas pelos pioneiros são sentidas tanto no estilo literário seco de Brandão, quanto no esforço teórico colossal por ele empreendido para dominar as fontes necessárias ao tratamento dos temas da realidade brasileira que compunham a visão global que lhe interessava.

Não foram poucos os comentadores que nos últimos anos protestaram contra o total esquecimento do pensamento de Octavio Brandão na historiografia do pensamento social brasileiro ${ }^{4}$. Se por um lado, Costa (2014) e Zaidan (1985) apontam para a importância do papel desempenhado pela classe trabalhadora no processo de redemocratização como condição para a revisão do papel dos comunistas pioneiros na política brasileira, por outro lado, autores como, Silva (1997), Amaral (2003), Del Roio (2004), Bianchi (2012), Moraes (2014), Lacerda (2015; 2019), D’Agostini (2019), entre outros, protestam contra o esquecimento unânime de Brandão por parte dos historiadores da esquerda brasileira até bem recentemente, contribuindo para o resgate da sua memória. Neste artigo pretendo me somar ao recente movimento de reapreciação do pensamento do autor, jogando luz sobre Canais e Lagoas, livro que pode ser considerado seu primeiro trabalho de fôlego, e cuja publicação completa cem anos este ano.

Pela ocasião do seu centenário, para além de uma apreciação crítica da obra, pretendo situá-la em sua evolução teórica e relacioná-la tanto com outros trabalhos de Brandão prévios, como a segunda conferência realizada em Maceió, publicada pelo

\footnotetext{
${ }^{2}$ Cargo análogo ao de vereador.

${ }^{3}$ Minervino de Oliveira nasceu no dia 1 de outubro de 1891, foi um tecelão, dirigente sindical e político pelo PCB. Nas eleições de 1930, Minervino foi o primeiro negro a concorrer à presidência do Brasil. Sobre a trajetória política de Minervino de Oliveira e mais detalhes sobre este acontecimento, ver Domingues (2017).

${ }^{4}$ É digna de nota a omissão de Astrojildo Pereira, que em sua Formação do PCB - 1922-1926 ([1962] 2012, p. 92), ao narrar o II Congresso do PCB, menciona a dicotomia agrarismo e industrialismo que servia de base à leitura da realidade brasileira do partido à época, sem mencionar a obra de autoria de Brandão que teria servido como seu fundamento. Bianchi (2012) sintetiza em seu texto os sucessivos ataques à memória de Octavio Brandão.
} 
Jornal do Comércio de Maceió, com o título de A mineralogia e a geologia dos Canais e Lagoas; como com trabalhos posteriores à publicação de Canais e Lagoas, tais como Agrarismo e Industrialismo, e O proletariado perante a revolução democrática pequenoburguesa.

\section{Um jovem militante entre canais e lagoas}

Octavio Brandão Rego nasceu em Viçosa ( $A L$ ) em 12 de setembro de 1896. Conhecida região canavieira ao centro de Alagoas, situava-se em suas proximidades o Quilombo dos Palmares, e sua paisagem e sua gente serviram de inspiração para romances de seu colega de classe no primário, Graciliano Ramos (BRANDÃO, 1978, p. 58). É em Viçosa que Paulo Honório, protagonista de São Bernardo ([1934] 2013), adquire propriedade, após fazer fortuna como mascate sertão adentro. Homem livre, caboclo, tentando ascender socialmente, entra em choque com os poderes oligárquicos da Primeira República e acaba enlouquecendo vitimado por sua própria ambição. Assim como os demais personagens que compõem a trama, os homens e mulheres dos romances de Graciliano Ramos encarnam trajetórias históricas possíveis para os indivíduos sociais da época, característica marcante do seu realismo ${ }^{5}$.

Personagem que tem sua trajetória confundida com as lutas políticas travadas pelos trabalhadores no limiar da Primeira República, Brandão é um tipo que poderia ser facilmente encontrado no universo de Graciliano Ramos. Nordestino do interior, que por muitas vezes em suas memórias se compara a figura do caboclo, Brandão tomou partido nas lutas de libertação nacional, na luta pelo petróleo, e nas lutas travadas pelo movimento operário, que então dava seus primeiros passos organizativos na direção da constituição de um partido político operário revolucionário. Como vários de seus contemporâneos, o autor transitou de uma síntese teórica que resultava da confluência do positivismo e do anarquismo, para o que ele, antes mesmo do termo tornar-se popular, chamou de "marxismo-leninsmo" ${ }^{6}$. Também influenciaram nesse processo as

\footnotetext{
${ }^{5}$ Carlos Nelson Coutinho (2011) obtém excelentes resultados aplicando o método marxista de crítica literária proposto por Lukács à obra de Graciliano Ramos. Seguindo as teses do realismo lukacsiano, Coutinho defende que em seus romances o autor apresenta uma imagem do Brasil na República Velha. ${ }^{6}$ Os comentadores divergem sobre o primeiro uso da expressão marxismo-leninismo. Enquanto Moraes (2007, pp. 41-43) afirma que Deborin empregou pela primeira vez a expressão em março de 1928, e que
} 
condições de recrudescimento da repressão sobre a atuação política dos anarcossindicalistas ao longo da última década da Primeira República - momento de seu declínio econômico e de sua disrupção política.

Sua vida familiar foi conturbada e um tanto quanto trágica. Sua mãe, Maria Loureiro Brandão Rego, faleceu quando ele tinha apenas quatro anos de idade, e ironicamente, a lembrança mais viva que possuía dela era seu velório. Este acontecimento marcaria de tal maneira Brandão, que o autor sempre que possível em seus escritos lembrava sua memória, tendo redigido uma extensa dedicatória para sua mãe em Canais e Lagoas. Brandão viveria um período com o tio, em um casebre tipicamente caboclo, no engenho do Barro Branco, retornando à Viçosa com o segundo casamento do pai. Lá estudou na Escola Primária Silva Jardim, onde relata ter travado o seu primeiro contato com o evolucionismo através de seu professor primário (BRANDÃO, 1978, p. 59). Ao mesmo tempo em que era rigoroso em sua educação, o pai de Brandão era um homem progressista que compartilhava de valores republicanos, cultivando um anti-imperialismo intuitivo, externado em suas críticas veementes à construção da estrada de ferro Great Western e ao czarismo russo.

Mas novamente a tragédia se abateria sobre a vida do autor, e Brandão perderia seu pai em 1911, quando já morava e estudava em Maceió, sob os auspícios de seu tio Alfredo Brandão. Matriculado no Colégio Marista, o filho que havia aprendido desde cedo com seu pai a questionar a hipocrisia, entrou em choque com o conservadorismo e a religiosidade tacanha imposta pelos padres. Dentre as poucas memórias boas do Colégio Marista, entre passeios e brincadeiras, Brandão relata sua grande amizade com o poeta Jorge de Lima. Em 1909, é matriculado pelo tio no Liceu Alagoano, onde, mesmo tendo maior liberdade em relação à prática religiosa, não consegue adaptar-se adequadamente e permanece distante de seus colegas de classe. Estas experiências o fizeram um jovem recluso e propenso à leitura. Ao concluir o ginásio, vai para Recife em 1912 estudar Farmácia, onde permaneceria por três anos, até 1914.

O clima intelectual com que se deparou Brandão ao chegar em Recife e do qual desfrutou ao longo da sua permanência, foi decisivo para sua formação nestes anos

Stalin só a utilizou em 1930, Bianchi (2012, p. 138) diverge, afirmando que a expressão foi utilizada por Zinoviev, em 1927, nas teses sobre a revolução chinesa, e Stalin só a empregaria em 1928. O que interessa aqui é que todas as datas são posteriores a Agrarismo e industrialismo, endossando o uso pioneiro do termo por Brandão. 
cruciais de juventude. A cidade possuía uma vida política e cultural viva e agitada. Passando por uma lufada de renovação intelectual de viés liberal nas primeiras décadas do século XX, em Recife originou-se um caldo cultural onde se amalgamavam positivismo, evolucionismo e monismo ontológico, que certamente serviriam como alimento para reflexão de Brandão (ZAIDAN, 1985, p. 33). Consequentemente, nestes anos o autor assimila tal ecletismo ideológico, consolidando uma base teórica que ficaria arraigada até os últimos dias de sua vida em sua visão de mundo, e que se apresentaria como um traço marcante de suas obras posteriores.

Seria em Recife que o autor teria seu primeiro contato com o materialismo filosófico através de Force et Matière ${ }^{7}$ (Força e Matéria) de Ludwig Buchner, escritor, médico e filósofo materialista alemão do século XIX, bastante influenciado pelas ideias de Darwin. Comprado por engano como um livro didático, Brandão relata a experiência da leitura em suas memórias: "Dei logo o primeiro passo libertador. Tornei-me partidário do materialismo filosófico - científico naturalista. Era o resultado de um lento processo que vinha desenvolvendo-se há tempos" (BRANDÃO, 1978, p. 68). O naturalismo monista herdado de Buchner levou-o ao interesse simultâneo pelas ciências naturais e pela realidade histórica, vistas como formas de ser qualitativamente semelhantes, articuladas em um longo e contínuo ciclo evolutivo. Absorveu o positivismo e o evolucionismo em sua formação através da leitura de naturalistas e geógrafos, como Darwin, Haeckel e Humboldt. Fascinado pela natureza, nestes anos começou a fazer incursões pelas matas nos arredores de Recife para estudar botânica, mineralogia e geologia (BRANDÃO, 1978, p. 71-73).

Nestes anos em Recife, Brandão inicia estudos de história e geografia do Nordeste, escrevendo em 1914 o artigo Aspectos Pernambucanos nos Fins do Século XVI, publicado no jornal de Recife, e transcrito pelo Instituto Arqueológico e Geográfico Pernambucano. Em suas memórias Brandão comenta o artigo:

Nesse estudo, procurei descrever as paisagens naturais e as condições históricas, econômicas e sociais de Pernambuco na época. Prenuncio do rumo que o autor seguiria, marcou o início de sua atividade propriamente literária e científica. Foi o começo da primeira etapa do desenvolvimento desta atividade que se prolongou até 1917 e se caracterizou por uma série de estudos de caráter nacional - sobre a História Natural, a Geografia, a Literatura e a História do Brasil. (BRANDÃO, 1978, p. 75).

\footnotetext{
${ }^{7}$ De título original Kraft und Stof (1854), o livro de Ludwig Buchner não possui edição em português.
} 
Formando farmacêutico em 1914 com uma tese sobre aspectos da botânica brasileira, tendo estudado "a família da labiadas em geral e a erva-cidreira em particular" (BRANDÃO, 1978, p. 79), Brandão retorna à Maceió praticando na farmácia de seu tio Manoel, no Bairro da Levada. Lá Brandão atendia gratuitamente trabalhadores rurais e trabalhadores urbanos engajados nas incipientes manufaturas locais. Nos finais de semana, aproveitava a biblioteca do Instituo Arqueológico e Geográfico Alagoano para realizar seus estudos sobre geologia, sendo um autodidata neste e em muitos outros assuntos. O autor também relata as dificuldades para consultar a coleção de gemas do Liceu Alagoano, tendo que estudar 150 minerais em um período de 15 dias, dispondo de apenas três horas diárias. Ao final da consulta, Brandão ainda foi acusado injustamente de ter furtado alguns exemplares da coleção (BRANDÃO, 2001, p. 158).

Nos anos seguintes Brandão deu um passo que seria decisivo em sua trajetória, e iniciou sua atuação na imprensa operária de Alagoas, contribuindo com o jornal Tribuna do Povo, que circulou em Viçosa entre 1916 e 1917. O periódico era editado por Antônio Bernardo Canellas, um jovem tipógrafo fluminense de apenas dezoito anos de idade, intensamente envolvido com o movimento anarquista no estado do Rio de Janeiro, e que viria a cumprir importante e controverso papel para a fundação do $\mathrm{PCB}^{8}$. Canellas encontrou na figura de Brandão, um jovem e assíduo colaborador político para as polêmicas tipicamente travadas nos jornais operários à época. A partir de então Brandão exerceria a atividade de articulista com certa regularidade pelo resto de sua vida, publicando em diversos jornais operários e conservadores. Juntamente com a farmácia e a atividade de tradução - é importante lembrar que Brandão foi o primeiro tradutor integral de O Manifesto Comunista no Brasil - o jornalismo foi a principal atividade remunerada exercida por Brandão ao longo de sua vida.

\footnotetext{
${ }^{8}$ Antônio Bernardo Canellas (1898-1936) foi militante anarquista e fundador do PCB, sendo designado como secretário internacional da primeira Comissão Central Executiva do partido. Canellas é conhecido pela sua participação polêmica no III Congresso da III Internacional Comunista, no qual as divergências por ele provocadas postergaram a aceitação do PCB como membro da IC. Por conta deste episódio Canellas também foi o primeiro membro expulso do PCB. O processo de sua expulsão ficou ao encargo de Octavio Brandão que declarou que "embora fossem louváveis os princípios do companheiro, ele não representara o PCB” (DULLES, 1977, p. 168).
} 
Entre 1916-1917, Brandão iniciou uma série de viagens pelas Lagoas Manguaba e Mundaú, muitas vezes subindo por seus canais rumo ao interior. Estas viagens dariam origem a Canais e Lagoas (2001), redigido entre 1917 e 1918, mas publicado como livro somente em 1919 após sua chegada ao Rio de Janeiro. Como resultado desta viagem, Brandão realizou duas palestras no ano de 1917 em Maceió: a primeira delas em 24 de fevereiro de 1917 no Teatro Deodoro; e a segunda em 12 de outubro de 1917 na sede do Instituto Arqueológico e Geográfico Alagoano, onde expunha os processos geológicos que haviam produzido as Lagoas Mundaú e Manguaba. Baseando-se em uma explicação evolucionista da origem das lagoas, Brandão aponta indícios da existência de petróleo, defendendo sua nacionalização. Com isso, Brandão conseguiu de uma vez só desagradar à Igreja Católica e às oligarquias locais. A segunda destas conferências foi publicada em janeiro de 1918, pelo Jornal do Comércio de Alagoas com o título de $A$ mineralogia dos Canais e Lagoas. Uma terceira conferência foi realizada no dia 31 de março de 1918 na sociedade Perseverança e Auxílio, associação mutualista dos caixeiros (trabalhadores do comércio) de Maceió (BRANDÃO, 1978, p. 89-90).

Em outubro de 1917 começou a circular em Maceió outro jornal operário, intitulado A Semana Social, editado pelo mesmo Bernardo Canellas. As manchetes propagandeadas pelo jornal à época destacavam a elevação da carestia de vida e a redução dos salários reais, resultado das sucessivas desvalorizações cambiais para sustentação da renda dos cafeicultores, conhecida consequência da política de valorização do café. Além disso, opunham-se à Primeira Guerra Mundial e à entrada do Brasil no conflito, segundo eles uma guerra imperialista entre as burguesias dos países centrais. Quando o Brasil entrou na guerra, A Semana Social publicou um artigo com a manchete "Abaixo a Guerra Imperialista", de autoria de Brandão. As autoridades fecharam diversos jornais por todo o país, dentre os quais $A$ Semana Social. A população favorável à entrada do Brasil na guerra, enfurecida, cercou a redação do jornal clamando pelo linchamento de Canellas e Brandão, acusados de crime de lesa pátria. Presos no interior da redação, o pior só não aconteceu porque uma moradora do prédio vizinho facilitou a fuga dos redatores pela saída dos fundos. Dali em diante Canellas iria para Recife e Brandão regressaria a Viçosa (DULLES, 1977, p. 62).

Enquanto isso, no Rio de Janeiro, à época capital federal, a derrota das greves ocorridas em 1917-1919, levaram à escalada da coerção policial e a deportação dos 
trabalhadores estrangeiros, meios estes amplamente utilizados pelo Estado para responder aos levantes e desarticular os sindicatos. A perseguição das lideranças fez com que José Oiticica, filho de um rico proprietário de terras, retornasse à Alagoas para se exilar. Brandão procurou Oiticica em sua propriedade para que prefaciasse Canais $e$ Lagoas, tendo este aceitado prontamente o convite (DULLES, 1977, p. 35). Os dois iniciariam então uma combativa militância e um sério trabalho de organização dos trabalhadores rurais e pescadores, além dos trabalhadores das incipientes indústrias têxteis que se desenvolviam na região.

Em sintonia com os militantes anarquistas de seu tempo, Brandão foi um entusiasta da Revolução Russa, fundando, em 1919, o Grupamento Comunista Libertário de Alagoas. A repercussão da Revolução no Brasil mostrou aos trabalhadores que seria possível fazer uma revolução comunista em um país de capitalismo pouco desenvolvido, predominantemente agrário, com similitudes com a formação econômico-social a brasileira. Como resultado de sua aproximação com os trabalhadores rurais, pescadores e o operariado nascente, Brandão criou a Congregação Libertadora da Terra e do Homem, que fazia trabalho de base entre operários, artesãos, intelectuais e empregados do comércio. Brandão também articulou o maior movimento grevista visto até então nas Alagoas, lutando pelo aumento salarial e pela redução da jornada de trabalho, em um contexto em que os trabalhadores enfrentavam então jornadas de 14 a 18 horas de trabalho e viviam com baixos salários, que, diante da elevação da carestia resultante das desvalorizações cambiais típicas nas economias agrário-exportadoras, não cobriam sequer suas necessidades básicas.

Após este levante, as autoridades de Maceió passam a suspeitar de um "complô maximalista" na cidade, que estaria dirigindo o movimento grevista. Brandão é preso quando vai visitar Rosalvo Guedes, um companheiro anarquista, na cadeia. Permanecendo preso por dois meses, sua família valeu-se da influência que tinha entre a burguesia local para liberá-lo, e ao fazê-lo, o secretário do interior disse que não mais se responsabilizaria por sua vida a partir daquele momento. Estava jurado de morte por um sicário da oligarquia local de nome Horato Maurício, pistoleiro político que receberia o título de chefe de polícia caso o executasse. No entanto, Brandão preferiu atrasar a promoção do pistoleiro, e com uma passagem comprada com o pseudônimo de Octavio de Melo Rego, partiu escondido para o Rio de Janeiro no dia 18 de maio de 1919, a bordo 
do navio Itapura. Na bagagem levava o manuscrito de Canais e Lagoas para publicação (MORAES, 2014, p. 16-17).

Ao chegar ao rio, diante do desinteresse do editor Leite Ribeiro pela obra, Brandão financiou a impressão com parcos recursos próprios: cerca de 1 conto e 750 mil réis, para uma pequena tiragem de aproximadamente 500 exemplares pela editora Jacinto Ribeiro, contendo apenas o primeiro dos seus dois volumes. Prefaciado por José Oiticica, o livro teve alguma repercussão à época, recebendo críticas de, Lima Barreto, Fábio Luz, Monteiro Lobato, entre outros; contudo, ao mesmo tempo foi hostilizado por críticos conservadores, como Tristão de Ataíde, Jackson de Figueiredo e Humberto de Campos, que denunciou que o livro possuía um "estilo bolchevique" (BRANDÃO, 1978, p. 147).

\section{A mineralogia dos Canais e Lagoas: analisando as conferências de 1917-18}

Antes da publicação de Canais e Lagoas, Brandão proferiu uma série de conferências em Maceió, entre 1917 e 1918. Nestas conferências o autor apresentava ao público as principais conclusões deduzidas de seus estudos de campo na região das Lagoas Manguaba e Mundaú, entre 1916 e 1917. Tomado uma canoa a motor na Boca da Levada no dia 20 de abril de 1916, Brandão iniciou suas viagens na região das lagoas, realizando cerca de 30 viagens e excursões, percorrendo 1600 quilômetros, dos quais 600 a pé. Tais excursões já tinham como propósito escrever o livro Canais e Lagoas, mas, para além disto, almejavam:

Conhecer diretamente a Terra e o homem trabalhador. Pesquisar a natureza viva, o povo e a história. Descobrir as riquezas naturais em geral e indícios de petróleo em particular. Coligir materiais folclóricos. Investigar a formação e desenvolvimento da terra, observar as condições de vida e de trabalho das populações. Conviver estreita e fraternalmente com os simples homens do povo - pescadores, canoeiros, lavradores pobres (BRANDÃO, 1978, p. 87)

Em suas incursões Brandão passou por intempéries e privações, fazendo penosas caminhadas, passando sede e fome, dormindo ao relento, contraindo doenças, e, em certa ocasião, quase naufragando com sua canoa. Mesmo assim, persistiu, avançando contra a correnteza de rios e riachos em direção ao interior do estado de Alagoas, 
deslocando-se a pé quando necessário. Não sem certa dose de ironia, seria nas proximidades de Maceió, na região do riacho do Broma, que Brandão encontraria os folhelhos petrolíferos com peixes fossilizados, classificados por ele como sendo da espécie dastilbe crandalli. Os indícios da existência de petróleo, procurados obstinadamente desde o princípio de suas incursões, foram finalmente encontrados. Estes resultados deram início a uma série de conferências.

A primeira conferência foi realizada no Teatro Deodoro, no dia 24 de fevereiro de 1917, em homenagem à Constituição da República. Esta conferência foi publicada na revista Pirausta, dirigida por seu parente e professor Moreno Brandão, tendo boa repercussão à época, de acordo com a avaliação do autor. Nesta ocasião, Brandão fala sobre as condições de trabalho adversas, em certa medida, decorrentes de seu esforço de pesquisa pioneiro para compreender a realidade brasileira, começando por seus arredores mais imediatos: "O que vou ler é um trabalho escrito entre os diversos acidentes da vida - entre trabalheiras estafantes em uma farmácia e disparadas pelas serranias ondulantes e pelos matagais violentos, cheia a alma do velho espírito desbravador dos Bandeirantes" (BRANDÃO, 2001, p. 159).

A segunda conferência, em homenagem a Cristóvão Colombo, ocorreu em 12 de outubro de 1917, na sede do Instituto Arqueológico e Geográfico Alagoano. Nesta conferência, publicada no Jornal do Comércio com o título de $A$ mineralogia dos Canais e Lagoas, diante de intelectuais e simples homens do povo, Brandão afirma ter consolidado um esquema a ser desdobrado, caminho que lhe serviria como uma "teoria bússola". A partir desta diretriz, que Brandão pretendia seguir com rigor, o autor propõe uma série de conferências, que abarcariam temas como os vegetais, os animais, o passado longínquo e a alma contemporânea das populações, entre tantos outros temas. Como se tornará perceptível mais à frente, estes temas reaparecem em alguma medida no primeiro volume de Canais e Lagoas.

O propósito do seu trabalho era contribuir para o conhecimento de recursos naturais aproveitáveis - não apensas o petróleo - para empregá-los como alternativa para solucionar as mazelas econômicas e sociais:

Para isso, tenho mergulhado na alma da nossa natureza e do nosso povo, mortificando-me com eles, sofrendo quando vejo a agonia dos "tabuleiros" ou a miséria em que vive a minha raça, pesquisando-lhes as verdades, 
inquirindo-Ihes as belezas, sondando-lhes as ansiedades com o imenso carinho, o profundo amor e a vocação suprema que sempre tive pelos estudos nacionais (BRANDÃO, 1918, p. 3).

Em uma conferência que se desdobra em cinco ciclos, no primeiro Brandão trata do nascimento da região, no segundo de sua evolução, no terceiro de sua fase atual, no quarto o autor oferece uma solução para o problema das enchentes, e, por fim, no quinto, propõe uma síntese de seu trabalho. Seu objetivo era aplicar seu pensamento às lagoas para descobrir "como a terra surgiu, como foi crescendo, como chegou a fase atual" (BRANDÃO, 1918, p. 23). Detendo-se longamente na formação e no desenvolvimento geológico dos terrenos percorridos, Brandão apresenta publicamente as provas favoráveis à existência de petróleo colhidas em suas pesquisas de campo: folhelhos petrolíferos, minerais e fósseis de plantas e peixes petrificados. Baseado nestas provas o autor previu a existência de petróleo em 14 lugares em Alagoas, procurando demonstrar a importância destas jazidas (BRANDÃO, 1918, p. 15-16). Em suas palavras: "Assim, em 1917, tornei-me pioneiro da luta pelo petróleo brasileiro. Contribuí, pois, para enriquecer o Brasil com um tesouro imenso e decisivo - o petróleo" (BRANDÃO, 1978, p. 89).

Do ponto de vista do método empregado na argumentação subjacente às conferências, Brandão comenta em suas memórias que esta segunda conferência demonstra que ele tinha superado inconsistências metodológicas anteriores, tornandose partidário de um "materialismo científico naturalista" e defensor de uma dialética espontânea - que Ihe servia como teoria do desenvolvimento universal. A despeito do caráter pessoal da avaliação, é importante considerar o fato de que este seria o tortuoso caminho a partir do qual o autor, formado em uma tradição cientificista e positivista, travaria o seu contato com a dialética e consolidaria seu "marxismo-leninismo".

Ao final desta segunda conferência Brandão apresenta 22 pontos que trazem as diretrizes do que se poderia chamar do embrião de uma agenda para o desenvolvimento econômico regional e nacional, procurando explorar plenamente o potencial dos canais e lagoas. Esta temática perpassa a totalidade da conferência, destacando, sempre que possível, as atividades úteis da economia da região, que deveriam ser aproveitadas, como, por exemplo, a cerâmica das olarias artesanais. Ao mesmo tempo, Brandão nunca 
perde de vista a necessidade de preservar, tanto o meio ambiente, quanto as atividades tradicionais.

Além da sugestão da realização de perfurações na tentativa de encontrar petróleo na região, o autor sugere também a exploração do granito para o calçamento das ruas, a proteção do solo massapê e das olarias artesanais, a avaliação para possibilidade de aproveitamento metalúrgico do solo, a proibição de pesca de curral, dentre outras medidas. Ainda que neste ponto da evolução intelectual de Brandão tal elemento ainda não se manifeste de forma tão clara, há sempre em sua reflexão a preocupação em estabelecer uma via de desenvolvimento capaz de superar os óbices ao desenvolvimento econômico brasileiro postos pelo imperialismo. Deste modo, é possível perceber desde já a afirmação de alguns dos traços básicos de um modelo de desenvolvimento nacional.

A terceira conferência, que versava sobre a flora e fauna dos "Tabuleiros Alagoanos", foi realizada no dia 31 de março de 1918, na sede da Sociedade Perseverança e Auxílio, associação mutualista dos caixeiros (trabalhadores do comércio) de Maceió, a convite de José Avelino e Silva. Na segunda parte desta conferência, Brandão enfocou os problemas sociais, apontando a saída revolucionária, que viria da divisão de terras e da instrução do povo, em sintonia com o que viria a ser o programa da Congregação Libertadora da Terra e do Homem. Nesta ocasião também afirma que, o trabalho que planejava era "um trabalho consciencioso, escrito com toda a alma, com meu imenso amor, com toda a fé nos destinos da Pátria. É pensando nela que escrevo" (BRANDÃO, 2001, p. 162).

As conferências tiveram boa repercussão, consolidando Brandão na cena acadêmica e política da capital alagoana. Além disso, enquanto proferia as conferências, o autor foi amadurecendo e fazendo pequenas reformulações no argumento apresentado em sua obra, tendo no contato com o público um acicate para a sua reflexão. Tamanho foi o sucesso das conferências, que Brandão começou a ministrar aulas de História Natural na Academia de Ciências Comerciais de Alagoas, instalada na sede da Sociedade Perseverança e Auxílio. Passo agora à avaliação de seu resultado textual através do resgate de alguns elementos de Canais e Lagoas.

\section{Revisitando Canais e Lagoas}


Obra projetada para ter dois volumes, mas que teve apenas seu primeiro volume publicado, Canais e Lagoas foi escrito principalmente entre 1916-1918, em Alagoas. Qualificado por seu autor como um "poema telúrico", o livro é uma obra de exaltação à terra e ao homem trabalhador de Alagoas e do Brasil, apresentando-se como um ensaio de interpretação histórica e geográfica destinado à análise dos problemas desta terra e desta gente. A obra preconiza o estudo da natureza como meio para levar o homem a uma nova interpretação do mundo e uma nova concepção filosófica e científica do universo. Isto porque, como observa Brandão em um prefácio da segunda edição da obra, em 1949:

O estudo da Natureza é o ponto de partida para o descobrimento das riquezas do país, para o seu desenvolvimento industrial, para a verdadeira industrialização, a criação da siderurgia, da alta metalurgia, a produção de meios de produção (BRANDÃO, 2001, p. 10)

Canais e Lagoas marca a maturação da visão de mundo formada pelo autor em sua juventude, que unia o desejo de conhecer a natureza e o desejo de transformar a sociedade (LACERDA, 2019, p. 135-137). O estilo do livro, segundo seu autor, pretende unir a ciência, a prática e a poesia, convocando à verdadeira descoberta do Brasil e do povo brasileiro. Assim como Brandão fala sobre sua primeira conferência, o estilo de Canais e Lagoas é revolto e desordenado, refletindo o estado de revolta e desordem em que se via o autor naqueles anos de sua juventude (BRANDÃO, 2001, p. 159).

Influenciado pelo pensamento crítico que surgia na Primeira República, a principal referência de Brandão para tratar das questões sociais brasileiras nestes anos é Euclides da Cunha, que não se reflete somente em seu estilo épico de escrita, mas também se impõe na estrutura da obra. Assim como Euclides, que organiza sua exposição em Os sertões ([1902] 2002) com a terra, o homem e a luta, Brandão pretende estudar a região, a gente e a história. Mas também estão presentes influências de seus estudos de ciências naturais do período imediatamente anterior, como, Buchner, Darwin, Haeckel, Humboldt. Em suma, Canais e Lagoas:

Procura explicar questões científicas com uma linguagem simples acessível, sem pedantismo. Continua a tradição de Euclides da Cunha. Marca uma 
ruptura com o academicismo e o bizantinismo dominantes. (BRANDÃO, 1978, p. 141).

Enquanto ensaio de interpretação histórica-natural, o livro também traz em si uma perspectiva antropológica, ou seja, uma visão do homem em geral, e também daquele homem que habita a região dos canais e lagoas. No plano mais geral das relações do homem com a natureza, Brandão percebe corretamente que o homem é parte integrante da natureza, mas não é um joguete em suas mãos, e sim um ser que também atua sobre a natureza, constituindo uma ação recíproca. Como nota no prefácio à segunda edição, ao passo que o homem primitivo não conseguia se libertar da natureza, o homem moderno, consciente, liberta-se cada vez mais deste domínio:

O homem não deve ser passivo diante da Natureza. Deve aspirar a integrarse nela. Ao mesmo tempo, deve aspirar a dominá-la e transformá-la. Deve atuar sobre a Natureza de um modo positivo e consciente, poderoso e radical. A consciência humana, recorrendo a todas as aquisições da ciência e da técnica moderna, deve dominar as forças da Natureza e utilizá-las em proveito da humanidade (BRANDÃO, 2001, p. 11)

Do ponto de vista do planejamento e da execução de Canais e Lagoas, como já foi mencionado, a obra foi planejada para ter dois volumes, tendo sido apenas o primeiro volume publicado, em 1919, no Rio de Janeiro, pelo editor Jacinto Ribeiro. No apêndice à segunda edição do primeiro volume, datada de 1949, seu aniversário de trinta anos, o autor apresenta um quadro do plano geral da obra, tal como formulado ainda nas duas conferências de 1917 (BRANDÃO, 2001, p. 153-156). Através da consulta deste plano, percebe-se que apenas a primeira parte da obra foi publicada - ou seja, menos de um terço do plano original, excluindo-se as partes que tratam da gente e da história. Também é possível constatar a partir da pesquisa documental realizada por Lacerda (2015), que a edição lançada em 1919 possuía apenas doze capítulos, sete capítulos a menos que a segunda edição. Faço referência neste artigo sempre à segunda edição.

À primeira vista o argumento realiza um grande voo panorâmico pela região dos canais e lagoas, contendo longas e detalhadas descrições geográficas e geológicas. Tal descrição, que começa por um sobrevoo, passa ao relevo, aos rios, canais, lagoas, ilhas, que perpassam os seis primeiros ciclos da história da terra. No sétimo ciclo, que versa 
sobre os minerais, Brandão não só elenca os minerais existentes na região, como se detém sobre as possibilidades de exploração econômica consciente dos recursos minerais disponíveis na região; são eles: arenito, granito, quartzos, além, é claro, dos folhelhos petrolíferos.

Do oitavo ao décimo ciclo o autor trata da história, do nascimento e da evolução da terra, chegando a fase atual no décimo primeiro ciclo. Os aspectos sociais aparecem no décimo segundo ciclo, quando o autor trata das enchentes que acontecem na região, tópico abordado no quarto ciclo de sua segunda conferência. Aqui, assim como naquela ocasião, o autor oferece uma análise da periodicidade das enchentes, propondo um esquema para prevê-las e mitigar os danos causados às populações autóctones. Destaca-se o tom de denúncia seguido pelo autor nesta passagem, que descreve o total esquecimento das populações por parte do Estado. Nos ciclos restantes o autor trata de aspectos climáticos e geológicos remanescentes, até chegar ao décimo-nono ciclo, no qual apresenta uma agenda de projetos para o melhoramento do Brasil, em grande medida similar ao projeto apresentado na segunda conferência de 1917. As diferenças existentes são marginais, e resultam apenas da reformulação do texto, que ao invés de ser apresentado como na segunda conferência com 22 pontos, é apresentado com 25 pontos, entre os quais figuram alguns pontos preexistentes reformulados e mais desenvolvidos, ou pontos preexistentes rearranjados.

Como visto, estas medidas pretendiam em linhas gerais, aproveitar os recursos minerais disponíveis na região, dentre eles o petróleo, para promover seu desenvolvimento econômico. Há duas coisas que devem ser destacadas em relação ao posicionamento de Brandão. Em primeiro lugar, indicando o início de uma tendência que iria se afirmar com maior nitidez em trabalhos posteriores, como Agrarismo $e$ Industrialismo, o desenvolvimento é encarado na perspectiva da conformação de um quadro nacional autônomo, e, portanto, opondo-se frontalmente às alternativas imperialistas de desenvolvimento. Em segundo lugar, o conhecimento científico da natureza almejado por Brandão traz sempre consigo a missão social de conhecer a natureza não só para melhor aproveitá-la, mas também aproveitá-la de novas maneiras 
e preservando-a 9 . Como o próprio autor reconhece, o homem é parte integrante da natureza, e o desenvolvimento da sociedade e da natureza, são processos imbricados.

Outro aspecto interessante de ser notado em Canais e Lagoas é a metodologia utilizada, caracterizada por seu autor como uma dialética espontânea e primitiva, e, em sua parte sobre geologia, comprova que "o estudo objetivo da Natureza Viva conduz à dialética. A Natureza é dialética por natureza" (BRANDÃO, 1978, p. 96). Na medida em que para Brandão o ser humano é um resultado do desenvolvimento da natureza, e o ser natural e o ser social são vistos como formas de ser qualitativamente semelhantes, fica evidente o modelo monista e cientificista que estrutura o naturalismo social do autor. Mesmo reconhecendo os avanços de seu ponto de vista em relação à ignorância reinante à época, Brandão aponta que uma das limitações de sua obra seria o desconhecimento da dialética científica de Marx e Engels ${ }^{10}$. Apesar de não ser uma obra da fase marxista do autor, Canais e Lagoas ilustra muito bem as bases teóricas monistas e positivistas sobre as quais estruturaria seu marxismo, e aponta para seu interesse pelas questões nacionais, nesta fase, ainda equacionadas em termos dos conceitos de povo e nação, e não de classes sociais, imperialismo e revolução.

Apesar de atacar o imperialismo britânico de maneira veemente, a ausência de uma análise detalhada do papel do imperialismo para os países dependentes, como o Brasil, é uma outra falha apontada por Brandão no prefácio à segunda edição de Canais e Lagoas, e também em suas memórias. Ou seja, embora criticasse o imperialismo o autor não explicava como se dava sua atuação e como seria possível superá-lo. Do mesmo modo, a terceira falha consistiria no fato de que as críticas ao latifúndio e a afirmação da necessidade de uma reforma agrária passam ao largo de uma análise da persistência do feudalismo e da questão agrária, o que torna os supostos encaminhamentos práticos elaborados por Brandão em fórmulas ocas. Isto também vale para a quarta falha, a crítica da organização social de um modo geral que "não mostra o caminho para a libertação social e nacional do Brasil. Esta é a quarta falha essencial da obra" (BRANDÃO, 2001, p. 17).

\footnotetext{
9 Por conta disso, Octavio Brandão é patrono de um prêmio de jornalismo ambiental anualmente promovido pela seção alagoa da Associação Brasileira de Saneamento Básico (ABES-AL), em parceria com o Sindicato dos Jornalistas Profissionais do Estado de Alagoas.

${ }^{10}$ É importante salientar que mesmo quando se aproxima do marxismo a dialética utilizada por Brandão mais se aproxima da tríade aristotélica tese-antítese-síntese, do que da dialética de Marx.
} 
Do ponto de vista das críticas recebidas pela obra e de sua repercussão, a obra teve alguma repercussão imediata, com críticas positivas de figuras como, Lima Barreto, Monteiro Lobato, o professor e militante anarquista Fábio Luz, o crítico e militante anarquista José de Oiticica, o crítico Nestor Victor e o historiador Rocha Pombo, entre outros. Canais e Lagoas foi comentado tanto em meios de comunicação da imprensa operária, como o semanário Spartacus, publicado no Rio de Janeiro, quanto em jornais de grande circulação como o Jornal do Brasil e a Gazeta de Notícias. Embora tenha tido esta repercussão imediata em meios específicos, tão logo o autor assume abertamente um posicionamento revolucionário, passa a ser recorrentemente hostilizado pela intelectualidade burguesa. Tanto em suas memórias, quanto no prefácio da segunda edição de Canais e Lagoas, o autor comenta as críticas de pensadores conservadores, como Jackson de Figueiredo, Tristão de Ataíde, Humberto de Campos e João Ribeiro. No geral, estes comentadores destacam que a obra não cumpre com aquilo que promete, definindo seu estilo literário como pernóstico e prolixo. Em relação aos pensadores que à época representavam o cânone, como Rui Barbosa e Afrânio Peixoto, Brandão relata a atitude de hostilidade ou no mínimo indiferença (BRANDÃO, 2001, p. 179-181; 1978, p. 143-148).

Em suma, destacam-se três elementos principais em Canais e Lagoas: o estudo da natureza e do homem, voltado à satisfação das necessidades humanas; a utilização consciente da natureza para promoção de um desenvolvimento econômico nacional, visto como o estabelecimento de um quadro nacional autônomo; e, o anti-imperialismo como elemento que impede a constituição deste quadro através do bloqueio ao acesso da satisfação destas necessidades, a condição de dependência econômica. Tendo analisado os principais elementos da obra, assim como suas limitações, para complementar este resgate mais do que necessário, na próxima seção procuro traçar as principais correspondências entre a reflexão desenvolvida em Canais e Lagoas e as obras seguintes de Octávio Brandão.

\section{Para além de Canais e Lagoas}

As temáticas tratadas por Brandão em Canais e Lagoas não representam um caso isolado em seu desenvolvimento intelectual. Embora tenha voltado sua reflexão mais 
diretamente às questões sociais, no sentido de construir uma interpretação da realidade brasileira, data deste período a constituição das fundações teóricas sobre as quais o autor construiu seu marxismo. Seu conhecimento das ciências da natureza reverbera em todo momento que autor nota a necessidade de aproveitar os recursos naturais para viabilizar o desenvolvimento nacional, libertando o país da dominação imperialista, ou quando aponta o atraso oriundo do modelo voltado à monocultura de exportação.

Tendo ingressado no Partido Comunista Brasileiro (PCB) um pouco após a sua fundação, ainda em 1922, com a tarefa de elaborar uma interpretação de realidade brasileira, Octavio Brandão foi o primeiro tradutor integral de $O$ Manifesto Comunista no Brasil. Em Agrarismo e Industrialismo: ensaio marxista-leninista sobre a revolta de São Paulo e a guerra de classes no Brasil - 1924 ([1926] 2006), Brandão avança em uma interpretação marxista da realidade brasileira que coloca a contradição agrarismo versus industrialismo como elemento determinante do desenvolvimento brasileiro ao longo da última década da Primeira República, tese e texto que serviram como base para as formulações do II Congresso do PCB, em 1924. As idas e vindas do deslocamento pendular do país em torno deste eixo seria a disputa imperialista entre o imperialismo estadunidense e o imperialismo britânico, aberta após a Primeira Guerra mundial. Enquanto o domínio do imperialismo estadunidense suscitava o desenvolvimento de uma burguesia industrialista e liberal, o domínio do imperialismo britânico tendia a bloquear e cercear o desenvolvimento desta burguesia, em favor da burguesia agrarista e semi-feudal, conservadora politicamente, que tinha na monocultura do café seu sustentáculo econômico.

Tanto em Agrarismo e Industrialismo, quanto em Rússia Proletária (1923) coletânea de artigos em que é feita uma apaixonada defesa a Revolução Russa, e um marco na transição de Octavio Brandão para o marxismo - reaparecem elementos de Canais e Lagoas, sobretudo a organização do desenvolvimento dos processos em questão através de ciclos evolucionários. Publicada pelo jornal A Voz Cosmopolita, Rússia Proletária divide-se em duas partes: a primeira trata dos indígenas - elementos pré-históricos nos termos do autor - e a segunda, dos elementos históricos. Esta última subdivide-se em quatro ciclos evolutivos: Primitivo, Medieval, Medievo-moderno e Moderno. Esta evolução culmina em uma última etapa, a Revolução Comunista, ainda por ocorrer, mas já previamente estabelecida. Com exceção do último, a ditadura do 
proletariado, todos os demais ciclos possuem uma divisão entre classes exploradoras e classes exploradas, que, na perspectiva do autor, são contradições moventes da evolução histórica brasileira. São avanços em Rússia Proletária a introdução dos conceitos de classe social e imperialismo, que passam a dividir espaço com os conceitos de povo e nação ${ }^{11}$.

O mesmo ocorre em Agrarismo e Industrialismo, onde o processo histórico de formação social do Brasil se desenrola a partir de ciclos, como é o caso, por exemplo, da análise das revoltas tenentistas e da história da classe trabalhadora brasileira. Enquanto no primeiro caso este tipo de raciocínio conduziu Brandão à hipótese central de sua teoria da revolução brasileira, de acordo com a qual uma terceira revolta tenentista, que sucederia as revoltas tenentistas de 1922 e 1924, se generalizaria em uma revolução comunista, o que em grande medida fundamentou a aliança do PCB com Luiz Carlos Prestes; no segundo caso, Brandão via a formação da classe trabalhadora brasileira como o desdobrar-se de ciclos iniciados com as greves de 1889, atingindo seu ápice nas greves de 1917, tendo superado as deficiências deste movimento anterior com a fundação do PCB, em 1922. A semelhança entre este arcabouço teórico e aquele subjacente à análise de Canais Lagoas é perceptível, por mais que o autor afirme que em Agrarismo e Industrialismo já era partidário de uma dialética materialista diferente daquela apreendida através do estudo prático da natureza.

A tese pioneira sobre a persistência do agrarismo serviria como base para crítica da questão agrária e da estrutura social presentes em Canais e Lagoas, apontando saídas mais factíveis para os problemas sociais. Tais saídas encontram-se consubstanciadas na estratégia democrática pequeno-burguesa para a revolução brasileira, sintetizada por Brandão ao final de Agrarismo Industrialismo e também em $O$ proletariado perante a revolução democrática pequeno-burguesa ([1928] 1985). A temática da luta pelo petróleo articula-se neste quadro como uma pauta que ilustra a necessidade de afirmar um projeto de desenvolvimento nacional, opondo-se à política imperialista dos plantadores de café, que volta o Brasil para a monocultura de bens primários de baixo valor adicionado. Além disso, as consequências sociais da política de valorização do café são as principais causas do processo de proletarização da pequena-

\footnotetext{
${ }^{11}$ Para uma análise comparativa entre Canais e Lagoas e Rússia Proletária, ver Lacerda (2015; 2019).
} 
burguesia, através da elevação do seu custo de vida, o que desencadearia o estopim da revolução democrática burguesa no Brasil nos termos de sua estratégia. Desse modo é possível compreender a importância dos elementos presentes nas primeiras obras de Brandão com aqueles elementos presentes nas obras da sua maturidade.

\section{Conclusões}

Na historiografia do pensamento o silêncio premeditado por parte dos pares é algo tão ou mais severo do que a mais violenta e impiedosa crítica. Passados quarenta anos da morte de Brandão e cem anos da publicação de Canais e Lagoas, e o silêncio em torno do livro, e também em torno do lugar de Brandão no pensamento social brasileiro como um todo, ainda causa incômodo. O referido esforço recente de diversos comentadores no sentido de reavaliar e explorar novas possibilidades interpretativas sobre a contribuição do autor é sintomática deste incômodo, ao mesmo tempo que indica a necessidade de reabilitar intelectualmente o legado e a obra de Brandão. Neste artigo procurei me somar a este esforço recente de reabilitação intelectual e resgate da memória do autor através da reconstituição da gênese de Canais e Lagoas no pensamento do autor, explorando algumas relações da obra com a produção imediatamente posterior de Brandão, localizada sobretudo ao longo dos anos 1920.

Canais e Lagoas une poesia e ciência, reflexão teórica e pesquisa empírica, para apresentar a saga da terra e da gente dos arredores de Maceió e do interior do estado de Alagoas, um povo acometido por toda a sorte de vicissitudes que o impediam de gozar de uma vida humanamente e politicamente emancipada. Para Brandão, essa emancipação não é possível sem o conhecimento científico da natureza e sua utilização para o desenvolvimento local e nacional, se opondo aos desígnios do imperialismo. Ao mesmo tempo, também não virá com o uso predatório e desmedido destes recursos, que frustra as possibilidades de um padrão de desenvolvimento econômico autônomo. Todos esses fatores são considerados decisivos do ponto de vista de Brandão para o estabelecimento de um quadro econômico e político nacional, embora à época da redação e edição de Canais e Lagoas ainda não dispusesse de uma análise teórica do imperialismo e da persistência do agrarismo, fatores que norteariam a reflexão do autor nos anos posteriores. 
Ao trazer novamente à tona a contribuição de Brandão, é possível compreender que, a despeito de suas evidentes limitações, como o cientificismo e o monismo ontológico, bem como o esquematismo de sua dialética, no que diz respeito à realidade brasileira sua reflexão ainda se mantém atual em diversos aspectos, oferecendo observações ainda hoje relevantes sobre estes aspectos. Desse modo, ainda hoje é urgente quebrar o silêncio em torno da obra de Brandão, extraindo dela suas lições em relação às questões concernentes ao desenvolvimento nacional, inspirado pelas mais duras condições enfrentadas pelo autor, e por toda sua tradição de pensamento social engajado e luta política.

\section{Referências}

AMARAL, Roberto Mansilla. Uma Memória Silenciada: Ideias, lutas e desilusões na vida do revolucionário Octavio Brandão (1917-1980). Niterói, 2003. Dissertação (Programa de PósGraduação em História) - Universidade Federal Fluminense.

BIANCHI, Alvaro. Octavio Brandão e o Confisco da Memória: nota à margem da história do comunismo brasileiro. Crítica Marxista, n 34, pp. 133-149. São Paulo: Editora UNESP, 2012.

BRANDÃO, Octavio. A Mineralogia dos Canais e Lagoas. Jornal do Comércio, janeiro 1918.

. Agrarismo e industrialismo: ensaio marxista leninista sobre a revolta de São Paulo e a guerra de classes no Brasil - 1924. 2a edição. São Paulo: Anita Garibaldi, [1926] 2006. Canais e Lagoas. Maceió: EDUFAL, [1919] 2001. Combates e Batalhas. Memórias. 1o volume. São Paulo: Alfa-Ômega, 1978.

O Proletariado Perante a Revolução Democrática Pequeno-burguesa. In: ZAIDAN, M. PCB (1922-1929): na busca das origens de um marxismo nacional. São Paulo: Global, [1928] 1985, pp. 121-132.

. Rússia Proletária. Rio de Janeiro: Voz Cosmopolita, 1923.

. Uma Etapa da História de Lutas. In: Brandão, O. Agrarismo e industrialismo: ensaio marxista leninista sobre a revolta de São Paulo e a guerra de classes no Brasil - 1924. $2^{\text {a }}$ edição. São Paulo: Anita Garibaldi, [1957] 2006, pp. 189-196.

COSTA, Emília Viotti. "A nova face do movimento operário na Primeira República." In: A dialética invertida e outros ensaios. São Paulo: Editora Unesp, 2014, pp. 135-156.

COUTINHO, Carlos Nelson. "Graciliano Ramos." In: Cultura e sociedade no Brasil: ensaios sobre ideias e formas. 3a edição. São Paulo: Expressão Popular, 2011, pp. 141-194.

D'AGOSTINI, Maria Stella. Perspectivas de um pensador marginal: Octávio Brandão. Argumentos, V. 16, n. 2, jul/dez, p. 18-39, 2019.

DEL ROIO, Marcos. "Octávio Brandão nas origens do marxismo no Brasil." Crítica Marxista, v. 1, n 18, pp. 115-132. São Paulo: Ed. Revan,, 2004.

DOMINGUES, Petrônio. Minervino de Oliveira: um negro comunista disputa a presidência do Brasil. Lua Nova - Revista de cultura e política, nº 101, p. 13-51. São Paulo, 2017. 
Disponível em: < http://www.scielo.br/pdf/ln/n101/1807-0175-In-101-00013.pdf> Acesso em 14/01/2021.

DULLES, John Foster. Anarquistas e Comunistas no Brasil. $2^{\mathrm{a}}$ edição. Rio de Janeiro: Nova Fronteira, 1977.

LACERDA, Felipe Castilho de. A "Transição de Octávio Brandão ao Marxismo: os livros Canais e Lagoas e Rússia Proletária." In: XXVIII SIMPÓSIO NACIONAL DE HISTÓRIA, Anais Eletrônicos. Florianópolis, 2015.2 Disponível em: <http://www.snh2015.anpuh.org/resources/anais/39/1427837065_ARQUIVO_snh2015_felipe-lacerda.pdf> Acesso em 14/01/2021.

Octavio Brandão e as matrizes intelectuais do marxismo no Brasil. Cotia: Ateliê Editorial. 2019.

MORAES, João Quartim. "A influência do leninismo de Stalin no comunismo brasileiro." In: MORAES, João Quartim \& REIS, Daniel Aarão. (Org.) História do marxismo no Brasil - Vol. 1 O Impacto das Revoluções. Campinas: Ed. Unicamp, 2007, pp. 47-88.

. “Octávio Brandão." In: PERICÁS, L. B. \& SECCO, L (org.). Intérpretes do Brasil: clássicos, rebeldes e renegados. São Paulo: Boitempo, 2014, pp. 13-28.

RAMOS, Graciliano. São Bernardo. Rio de Janeiro: Record, [1934] 2013.

SILVA, Ângelo José. "Agrarismo e industrialismo: uma primeira tentativa marxista de interpretação do Brasil.", Revista de Sociologia e Política, n. 8, pp. 43-55. Curitiba: 1997.

ZAIDAN, Michel. PCB (1922-1929): na busca das origens de um marxismo nacional. São Paulo: Global, 1985. 